\title{
Diagenetic constraints on the drivers of Capitan Reef encrustation
}

\author{
ROGER N BRYANT ${ }^{1}$, THEODORE PRESENT ${ }^{2}$ AND \\ CLARA BLÄTTLER ${ }^{1}$ \\ ${ }^{1}$ University of Chicago \\ ${ }^{2}$ California Institute of Technology \\ Presenting Author: rnbryant@uchicago.edu
}

The Capitan Reef complex in West Texas is famous for its unusually high prevalence of seafloor-encrusting carbonates for a Phanerozoic platform, leading some to suggest that PreCambrian styles of carbonate sedimentation enjoyed a Permian encore. Here, we use stable $\mathrm{Ca}, \mathrm{C}$ and $\mathrm{S}$ isotopes to try to pinpoint the environmental driver(s) of the enigmatic seafloor encrustation. We find that more ${ }^{44} \mathrm{Ca}$-enriched calcites show an enrichment in ${ }^{12} \mathrm{C}$ and have $\mathrm{S}$ isotopes that approach the inferred composition of Permian seawater sulfate. Microbial sulfate reduction must have been spatially or temporally coincident with recrystallization of primary carbonate phases, such that substantial phreatic ${ }^{34} \mathrm{~S}$-enriched sulfate was incorporated into diagenetic calcite. Moreover, the magnitude of ${ }^{34} \mathrm{~S}$-enrichment of carbonates relative to seawater was strongly influenced by local diagenetic conditions, with advection-dominated early marine cements, shelf, reef, and upper slope preserving more seawaterlike $\mathrm{S}$ isotope ratios than the diffusion-dominated lower slope. As some samples show greater ${ }^{34} \mathrm{~S}$-enrichments relative to contemporaneous seawater than those from modern sites in similar depositional environments, this raises several possibilities. For some facies, sedimentary parameters (e.g., grain size, porosity, organic matter rain rate) might have especially favored substantial incorporation of isotopically evolved sulfate. Additionally, the sulfate concentration in the Delaware Basin might have been slightly lower than modern levels, leading to more extensive isotopic evolution of sulfate in the zone of carbonate recrystallization. If the latter is true, it is possible that one driver of the high degree of seafloor encrustation in the Capitan Reef was an elevated water column $\left[\mathrm{Ca}^{2+}\right]:\left[\mathrm{SO}_{4}{ }^{2-}\right]$ ratio. 